\title{
Tubular Micro-Discectomy Under Local Epidural Anaesthesia: A Technical Note
}

\author{
Arvind Gopalrao Kulkarni, Sagar B. Sharma, Tushar S. Kunder \\ Department of Orthopaedics, Mumbai Spine Scoliosis and Disc Replacement Centre, Bombay Hospital, Mumbai, India
}

Corresponding Author: Arvind Gopalrao Kulkarni, MS Department of Orthopaedics, Mumbai Spine Scoliosis and Disc Replacement Centre, Bombay Hospital, Marine Lines, Mumbai, 400020, India

Tel: $+91-98-92875490$

Fax: +91-22-22080871

E-mail: drarvindspines@gmail.com

Received: February 10, 2019

Revised: June 4, 2019

Accepted: June 11, 2019

Objective: Day-care surgery maximizes utilization of healthcare and aids in early return to work. Minimally invasive spine surgery (MISS) under local epidural anesthesia is a step in this direction. The combination of minimal surgical trauma and nominal sedation results in quick recovery and early discharge. To present our experience of performing lumbar tubular micro-discectomy under local epidural anaesthesia. Methods: A case report of 10patients operated for lumbar herniated discs under local epidural anaesthesia. The patients had radicular pain since a few months with MRI evidence of herniated nucleus pulposus and failure of 6 weeks of conservative trial before surgery. The outcomes were assessed with ODI, VAS and Mac-Nab criteria. Premedication with Dexmedetomidine, local infiltration of lignocaine and bupivacaine with bolus dose of fentanyl during root manipulation facilitated the execution of the procedure. Results: All patients obtained dramatic pain relief postoperatively. The procedure was well tolerated except for the slight discomfort during varying degrees of nerve-root retraction. Patients were made to walk and oral diet allowed after an hour and discharge was within 24 hours of the procedure. The VAS improved from 8.4 to 2.3 and ODI from 58.2 to 22.8 . Follow-up was at $1,6,12$ and 24 weeks. No complications such as dural tear, nerve root injury etc. were seen. Conclusion: Microtubular discectomy under local epidural anaesthesia is a feasible option in experienced hands. Apart from reducing the effects of general anaesthesia, it reduces the hospital stay and cost. It is an evolution of microtubular discectomy towards day care surgery.

Key Words: Day care spine surgery, MED in local epidural anaesthesia, Microtubular discectomy, MED, Lumbar disc herniations

\section{INTRODUCTION}

Daycare surgery maximizes the utilization of healthcare and promotes early return to work ${ }^{4,12,15)}$. Minimally invasive spine surgery (MISS) under local epidural anesthesia is a step in this direction. The combination of minimal surgical trauma and nominal sedation results in quick recovery and early discharge ${ }^{1)}$. The authors present their experience of performing tubular lumbar micro-discectomy (MED) under local epidural anesthesia.

\section{MATERIALS AND METHODS}

Ten patients underwent MED for lumbar disc herniation under local epidural anesthesia with mild sedation. The patients had radicular pain since a few months and were given at least 6 weeks of conservative trial before surgery. The demographic data of the patients in terms of age, sex, involved dermatome and BMI were recorded (Table 1). VAS and ODI were noted pre and post-operatively. The MRI films were reviewed to determine the level, side, size and location of the herniation. Postoperatively, all patients were mobilized the same day and discharged the following day. Mac-Nab criteria was utilized to assess the outcome.

\section{OPERATIVE TECHNIQUE}

It is necessary to keep the patient nil by mouth for at least 4 hours before the procedure. In the preoperative room, the patient is pre-medicated with a Dexmedetomidine infusion 15-20 minutes before the procedure in a loading dose of $1 \mu \mathrm{g} / \mathrm{kg}$. 15 minutes later the infusion is tapered to $0.2 \mu \mathrm{g} / \mathrm{kg} / \mathrm{hr}$ and continued throughout the procedure ${ }^{9)}$. It is necessary to monitor the pulse, heart rate, ECG and blood pressure. In the operation theatre, pillows are used instead of bolsters for cushioning. The patient is properly counseled regarding the procedure. The patient is made to lie prone on the operating table with head turned to one side for comfort. Music is played to relax the 
Arvind Gopalrao Kulkarni, et al.

Table 1. Demographic data and outcomes

\begin{tabular}{|c|c|c|c|c|c|c|c|c|c|c|}
\hline Sr No. & Age & Sex & $\mathrm{BMl}$ & Diagnosis & $\begin{array}{c}\text { Preop VAS } \\
\text { Score }\end{array}$ & $\begin{array}{c}\text { Postop VAS } \\
\text { Score }\end{array}$ & $\begin{array}{l}\text { Preop ODI } \\
\text { Score }\end{array}$ & $\begin{array}{c}\text { Postop ODI } \\
\text { Score }\end{array}$ & $\begin{array}{l}\text { Operative time } \\
\text { (mins) }\end{array}$ & Mac Nab grading \\
\hline 1 & 37 & $\mathrm{M}$ & 23.5 & L5S1 $\mathrm{HNP}^{\dagger}$ & 9 & 2 & 60 & 26 & 90 & Excellent \\
\hline 2 & 47 & $\mathrm{~F}$ & 24.2 & L5S1 HNP & 8 & 3 & 60 & 24 & 75 & Excellent \\
\hline 3 & 45 & M & 23.4 & L4L5 HNP & 9 & 3 & 58 & 20 & 75 & Excellent \\
\hline 4 & 32 & $\mathrm{~F}$ & 22.6 & L5S1 HNP & 8 & 2 & 56 & 22 & 80 & Excellent \\
\hline 5 & 36 & $F$ & 26.4 & L4L5 HNP & 9 & 2 & 62 & 28 & 85 & Excellent \\
\hline 6 & 28 & M & 25.0 & L5S1 HNP & 8 & 3 & 54 & 20 & 70 & Excellent \\
\hline 7 & 32 & M & 24.2 & L4L5 HNP & 8 & 2 & 58 & 22 & 65 & Excellent \\
\hline 8 & 34 & M & 22.8 & L4L5 HNP & 9 & 2 & 60 & 24 & 65 & Excellent \\
\hline 9 & 42 & $\mathrm{~F}$ & 24.3 & L4L5 HNP & 8 & 2 & 56 & 20 & 60 & Excellent \\
\hline 10 & 38 & $M$ & 27.2 & L5S1 HNP & 8 & 2 & 58 & 22 & 60 & Excellent \\
\hline
\end{tabular}

${ }^{\dagger}$ Herniated Nucleus pulposus.
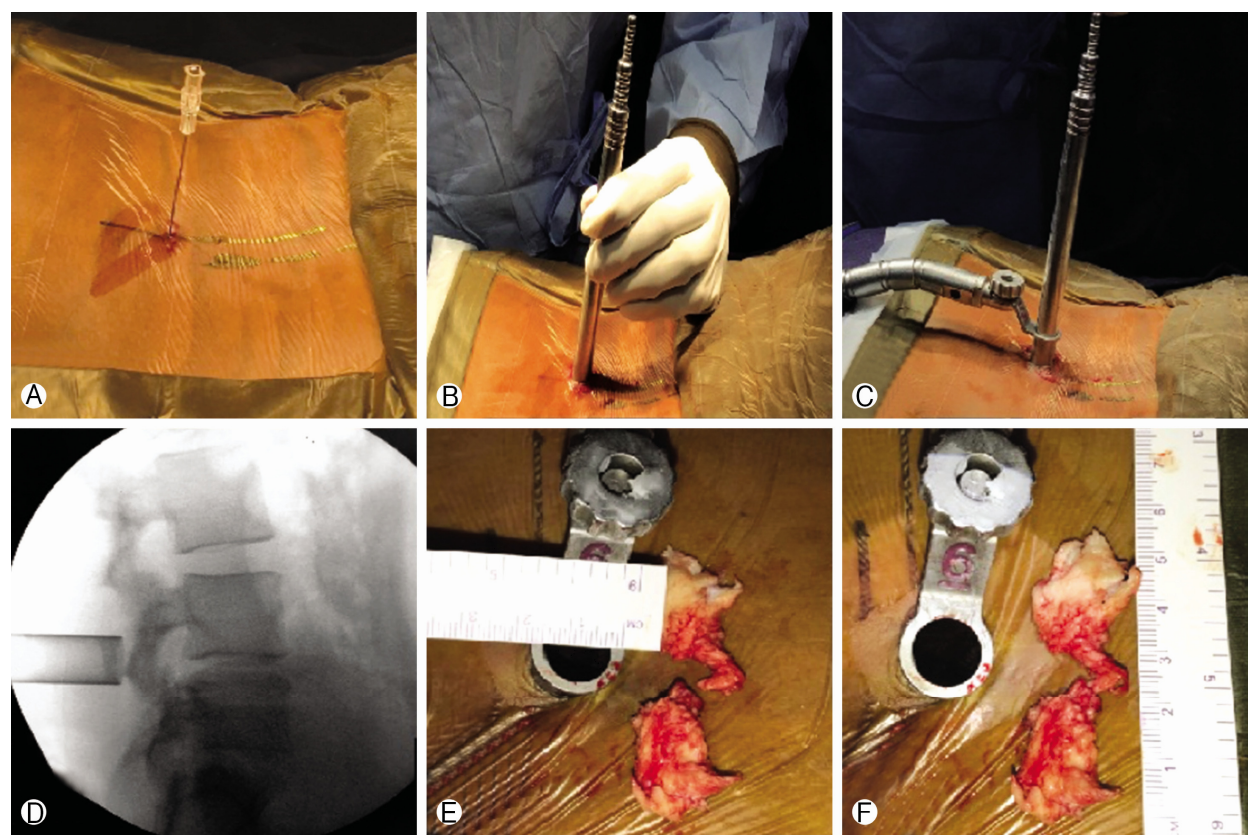

Fig. 1. (A) Localization of level and infiltration of local anaesthetic agent, (B) Insertion of serial dilators and (C) Docking of tubular retractor using flexible arm, (D) Intraoperative Fluoroscopic Image showing docking of tube at affected level, (E) working corridor of the tube and $(\mathrm{F}$ the extracted disc material.

patient and dampen the noise of the operating room. The operative level is localized under C-Arm. A mixture of $10 \mathrm{cc}$ of $2 \%$ lignocaine and $10 \mathrm{cc}$ of $0.5 \%$ bupivacaine is used for local infiltration using a $23 \mathrm{G}$ spinal needle, such that the trajectory of the needle bisects the intervertebral disc. Appropriate targeting of the laminotomy site during infiltration is imperative. The skin, soft tissue and periosteum is infiltrated with the mixture. After incising the skin with a 14-16 mm long incision at a site about $1 \mathrm{~cm}$ paramedian centered over the point of entry of the infiltration needle, serial dilators are inserted followed by docking of appropriately sized tubular retractor. The infiltra- tion allows painless drilling of the lamina to create a bony window. The ligamentum flavum handling doesn't cause discomfort to the patient. After the laminotomy, flavotomy is done and the dura with nerve root is exposed. At this stage, two crucial steps are application of a gelfoam soaked in $2 \%$ lignocaine over the nerve root and dura and Instant intravenous injection of Fentanyl $100 \mathrm{mcg}$. It is necessary to wait for a few minutes for the local anesthetic to act. Gentle manipulation of the nerve root is essential. Herniated fragment is then fished out using a nerve hook and pituitary forceps. The wound is then closed with absorbable sutures (Fig. 1). 


\section{RESULTS}

All patients experienced dramatic pain relief post-operatively, The procedure was well tolerated except for the slight discomfort felt during varying degrees of nerve-root retraction. The mean VAS improved from 8.4 to 2.3. ODI improved from a mean of 58.2 to 22.8 (Fig. 2)(Table 1). No complications such as dural tear, nerve root injury, wound infection etc. were seen. All patients were made to walk and have oral nutrition within an hour post-surgery. Mild analgesics were required to counteract the post-operative pain. The patients were discharged within $24 \mathrm{hrs}$ of the procedure. The benefit was sustained in the post-operative period at 1, 6, 12 and 24 weeks.

\section{DISCUSSION}

Use of local anaesthesia in spine surgeries dates back to 1926, Towne reported 4 laminectomies for tumour removal under local anaesthesia ${ }^{16)}$. Most articles mention the use of local anaesthesia for spine surgeries in high risk subjects (ASA class iii and iv) ${ }^{10)}$. In the modern era, local anaesthesia in spine surgeries is generally used for Trans-foraminal endoscopic discectomies $^{5,11,14)}$. According to our knowledge, there are only few reports of the use of local epidural anaesthesia in MED. Pharmacological innovations and MISS have made the idea of day care spine surgery conceivable. The patient is pre-medicated

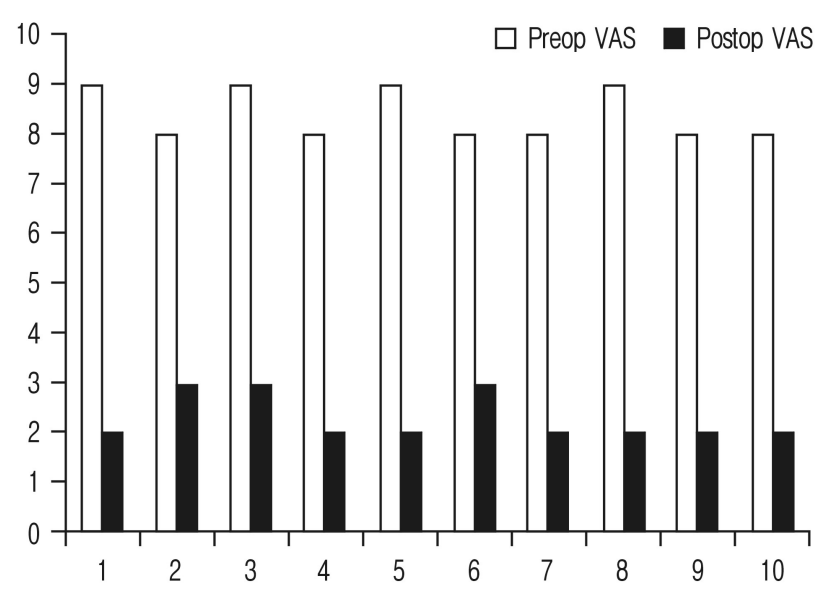

Fig. 2. Preoperative and Postoperative VAS score. with Dexmedetomidine. It is a selective $\alpha$ 2-adrenoreceptor agonist ${ }^{8)}$. It has sedative and analgesic properties with short duration of action. Unlike opioids and other sedatives like propofol, it achieves its effect without causing respiratory depression. Dexmedetomidine induces sedation by decreasing activity of noradrenergic neurons in the locus ceruleus in the brain stem, thereby increasing the activity of inhibitory gamma-aminobutyric acid (GABA) neurons in the ventrolateral preoptic nucleus. In contrast, other sedatives like propofol and benzodiazepines directly increase activity of GABA neurons. Sedation by Dexmedetomidine emulates natural sleep. Dexmedetomidine has less amnesia compared to benzodiazepines and also has analgesic effects at the spinal cord level and other supraspinal sites. The recommended dose of the same is $1 \mu \mathrm{g} / \mathrm{kg}$ stat over $15-20 \mathrm{mins}$ followed by $0.2 \mathrm{\mu g} / \mathrm{kg} / \mathrm{hr}^{2)}$. Dexmedetomidine is known for its arousable sedation without respiratory depression. It also does not alter the cardiovascular system and maintains hemodynamic stability ${ }^{2)}$. Overdose may cause bradycardia and hypotension ${ }^{7)}$. It is important to know the maximum permissible dose of lignocaine and bupivacaine for local infiltration (Table 2) ${ }^{13)}$. Overdose of lignocaine can cause seizures, respiratory depression and ventricular rhythm abnormalities and that of bupivacaine can cause cardio toxicity ${ }^{3,6)}$. It is important to counsel the patient before starting the procedure. This is particularly important in MED as the tubular retractor is fixed to the operating table. Sudden unanticipated movements of the patient after tube docking can alter the position of the tube and, in unfortunate cases, may run the risk of damaging the neural structures. Hence it is necessary that the patient is compliant and remains still during the procedure. It is important for the surgeon to execute the procedure swiftly, since prone position is uncomfortable for prolonged periods. The familiarity with the use of tubes, microscope and the art of meticulous hemostasis cannot be underestimated. Diligent and tactful use of burr to create laminotomy adjacent to the site of herniation is crucial since time is valuable in such cases. Inappropriate delays in sorting instruments and solving technical hitches only increases patient discomfort. It is important that the scrub nurse and the surgical assistant are scrubbed in before the patient is positioned. It is imperative that all the necessary instruments are ready over the trolleys, the C-Arm and the microscope are draped and the necessary drugs and disposables required for infiltration are ready before the patient is positioned. It is necessary to continuously interact with the patient during the procedure and caution him/her whenever a painful stimulus is anticipated. It is also necessary to use heating devices to

Table 2. Maximum safe dose of lignocaine and bupivacaine for local infiltration

\begin{tabular}{lllcc}
\hline \hline & Concentration used & \multicolumn{1}{c}{ Maximum safe dose } & $\begin{array}{c}\text { Maximum safe dose in mg } \\
\text { for a } 70 \mathrm{~kg} \text { adult }\end{array}$ & $\begin{array}{c}\text { Maximum volume that can } \\
\text { be safely infiltrated }\end{array}$ \\
\hline Lignocaine & $2 \% \mathrm{w} / \mathrm{v}$ & $4.5 \mathrm{mg} / \mathrm{kg}$ (without adrenaline) & $315 \mathrm{mg}$ & $15.75 \mathrm{~mL}$ \\
& & 7 (with adrenaline) & $490 \mathrm{mg}$ & $24.5 \mathrm{~mL}$ \\
Bupivacaine & $0.5 \% \mathrm{w} / \mathrm{v}$ & $2 \mathrm{mg} / \mathrm{kg}$ (with adrenaline) & $140 \mathrm{mg}$ & $28 \mathrm{~mL}$ \\
& & $3 \mathrm{mg} / \mathrm{kg}$ (without adrenaline) & $210 \mathrm{mg}$ & $42 \mathrm{~mL}$ \\
\hline
\end{tabular}


maintain a comfortable environment for the patient. Execution of MED under local epidural anaesthesia works similar to a wakeup test as the movements can be easily assessed. This prevents the surgeon from excessively manipulating and/or damaging the root, thus providing real time monitoring of the same.

\section{CONCLUSION}

MED in local epidural anaesthesia is a feasible option in experienced hands. A team effort is imperative to streamline the course of action and increase the operational efficiency. It helps in reduction of adverse effects of general anaesthesia, hospital stay and cost. Our technique can be considered as evolution of MED towards day care surgery.

\section{Disclosure}

The authors report no conflict of interest concerning the materials or methods used in this study or the findings specified in this paper

\section{REFERENCES}

1. Arts M, Brand R, van der Kallen B, à Nijeholt G L, Peul W: Does minimally invasive lumbar disc surgery result in less muscle injury than conventional surgery? A randomized controlled trial. European Spine Journal 20(1):51-57, 2011

2. Aryan HE, Box KW, Ibrahim D, Desiraju U, Ames CP: Safety and efficacy of dexmedetomidine in neurosurgical patients. Brain Injury 20(8):791-798, 2006

3. Badui E, Garcia-Rubi D, Estañol B: Inadvertent massive lidocaine overdose causing temporary complete heart block in myocardial infarction. American Heart Journal 102(4):801-803, 1981

4. Best NM, Sasso RC: Outpatient lumbar spine decompression in 233 patients 65 years of age or older. Spine 32(10):11351139, 2007

5. Chen HT, Tsai $\mathrm{CH}$, Chao SC, et al: Endoscopic discectomy of L5-S1 disc herniation via an interlaminar approach: Prospective controlled study under local and general anesthesia. Surgical Neurology International 2, 2011

6. Davis NL, de Jong RH: Successful resuscitation following massive bupivacaine overdose. Anesthesia \& Analgesia 61(1):6264, 1982

7. Devabhakthuni S, Pajoumand M, Williams C, et al: Evaluation of dexmedetomidine: safety and clinical outcomes in critically ill trauma patients. Journal of Trauma and Acute Care Surgery 71(5):1164-1171, 2011

8. Gertler R, Brown HC, Mitchell DH, Silvius EN. Dexmedetomidine: a novel sedative-analgesic agent. In Baylor University Medical Center Proceedings. Taylor \& Francis 14(1):13-21, 2001

9. Hall JE, Uhrich TD, Barney JA, Arain SR, Ebert TJ: Sedative, amnestic, and analgesic properties of small-dose dexmedetomidine infusions. Anesthesia \& Analgesia 90(3):699-705, 2000

10. Khan MB, Kumar R, Enam SA: Thoracic and lumbar spinal surgery under local anesthesia for patients with multiple comorbidities: A consecutive case series. Surgical Neurology International 5(Suppl 3):S62, 2014

11. Oksar M: Sedation for percutaneous endoscopic lumbar discectomy. The Scientific World Journal 2016

12. Pugely AJ, Martin CT, Gao Y, Mendoza-Lattes SA: Outpatient surgery reduces short-term complications in lumbar discectomy: an analysis of 4,310 patients from the ACS-NSQIP database. Spine 38(3):264-271, 2013

13. Rosenberg PH, Veering BT, Urmey WF: Maximum recommended doses of local anesthetics: a multifactorial concept. Regional Anesthesia and Pain Medicine 29(6):564-575, 2004

14. Sanusi T, Davis J, Nicassio N, Malik I: Endoscopic lumbar discectomy under local anesthesia may be an alternative to microdiscectomy: A single centre's experience using the far lateral approach. Clinical Neurology and Neurosurgery 139:324-327, 2015

15. Tomaras CR, Blacklock JB, Parker WD, Harper RL: Outpatient surgical treatment of cervical radiculopathy. Journal of Neurosurgery $87(1): 41-43,1997$

16. Towne EB: Laminectomy and removal of spinal cord tumors under local anesthesia. California and Western Medicine 24(2): 194, 1926 